\title{
Internet Addiction Among Iranian Students of Medical Sciences
}

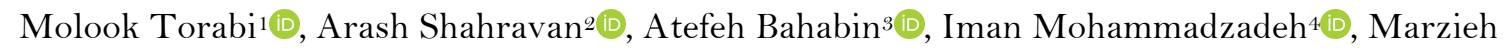 \\ Karimi Afshar1(10
}

${ }^{1}$ Social Determinants on Oral Health Research Center, University of Medical Sciences, Kerman, Iran.

${ }^{2}$ Endodontology Research Center, University of Medical Sciences, Kerman, Iran.

${ }^{3}$ School of Dentistry, Kerman University of Medical Sciences, Kerman, Iran.

${ }^{4}$ Oral and Dental Diseases Research Center, Kerman University of Medical Science, Kerman, Iran.

Author to whom correspondence should be addressed: Marzieh Karimi Afshar, Orthodontics Department, School of Dentistry, Kerman University of Medical Sciences, Shafa Ave, Jomhoori Islami BLVD, Kerman 7618759689, Iran. Phone: +98343211902 1. E-mail: marzieh.k.afshar@gmail.com.

Academic Editors: Alessandro Leite Cavalcanti and Wilton Wilney Nascimento Padilha

Received: 14 November 2019 / Accepted: 13 March 2020 / Published: 26 March 2020

How to cite this article: Torabi M, Shahravan A, Bahabin A, Mohammadzadeh I, Afshar MK. Internet addiction among Iranian students of medical sciences. Pesqui Bras Odontopediatria Clín Integr. 2020; $20: e 5387$. https://doi.org/10.1590/pboci.2020.056

\begin{abstract}
Objective: To identify the prevalence of Internet addiction (IA) and associated factors among Iranian medical students. Material and Methods: The cross-sectional survey was conducted on a random sample of 400 students. The self-administered questionnaire consisted of two sections: the first section was sociodemographic data, data about student's relations, and Internet use characteristics; the second part aimed at assessment of the level of IA using Young's 20-item scale for IA. Data analyzed in SPSS 20 at 0.05 significant level. Results: Considering their familiarity with the Internet, $80.3 \%$ stated personal experience and $12.3 \%$ individuals stated educational periods held outside the university. The most locations of using the Internet were dormitories (21.0\%) and houses (43.5\%). Concerning hours of Internet use, $45.2 \%$ used the Internet more than two hours per day. One hundred sixty-eight individuals $(42.0 \%)$ stated that they used the Internet less than $15 \%$ for university activities. One hundred eighty-eight individuals $(47.0 \%)$ used VPN and $75.5 \%$ were dissatisfied with Internet speed $61.2 \%$. A total of $64.3 \%$ had a poor dependency on the Internet and the prevalence of IA was $3.5 \%$. The mean score of IA questionnaire was $43.98 \pm 15.92$ from 125. The mean score of IA was higher in the male sex, but there was no significant correlation between sex and IA $(\mathrm{p}>0.05)$. There was not a significant correlation between the field of study and the year of entrance. Conclusion: The prevalence of Internet addiction among medical students was low. Identification of factors associated with IA can help in the planning of preventive programs to raise students' knowledge about the hazards IA.
\end{abstract}

Keywords: Internet-Based Intervention; Behavior, Addictive; Students, Medical. 


\section{Introduction}

The Internet changed the nature of communications in the 2oth century dramatically and such change is more often true about adolescents who are known as Net generation [1]. The Internet is one of the social communication tools. It is inexpensive and fast. The necessary information can be obtained by connection to Internet from everywhere without time limitation. The information available on the Internet is more often upto-date and this is the reason why it has been turned into a proper tool for following scientific advancements $[2]$.

It has been indicated that Internet users are more creative and more self-efficient than those who do not use the Internet [3]. The overuse of Internet can be dangerous for physical health and human thoughts [4]. The term "internet addiction" was proposed by Dr. Ivan Goldberg in 1995 due to pathologically compulsive internet use [5]. Internet addiction is a new and attractive topic and it is considered as a behaviororiented dependency [6]. Those who are highly dependent on the internet use it for watching films and cartoons, listening to music, playing computer games, membership of social networks and chat rooms. In contrast, normal users use it for reading news, events, education and searching for university websites. In addition, those who are dependent on Internet, use it aimlessly in private places [7].

Like drug addiction and other dependencies, Internet addiction is a real addiction. Such addiction is a chronic, recurrent and pervasive event followed by severe physical, economic, familial, social and mental impairments [8]. Studies indicated that the overuse of Internet had an adverse effect on the mental health of students. Those who overused the Internet had more mental problems and pathologies than the students who did not have such experiences [9]. Seventy-four percent of Indian adolescents used the Internet moderately and $7 \%$ of them overused it [1]. Prevalence use of the Internet among dental and medical students was high $[10]$.

It has shown the pooled prevalence of Internet addiction in medical students is five times than the general population [11]. Previous research showed that students addicted to the Internet had less complex practices than normal individuals. Also, they were less able to process information and control motivations [12]. Internet addiction in young individuals is a health problem all around the world [13].

Therefore, in continuing our interest in the medical research [14-18], the present research was conducted on Iranian students of medical sciences to consider increase in application of Internet, it's inevitable role in students' research activities, importance of students' mental health, their role in future and lack of information in this regard.

\section{Material and Methods}

Study Design and Sample

This is a cross-sectional descriptive research conducted on 400 individuals who were selected randomly. Students of Kerman Medical Sciences University, who had passed two academic semesters at this university, entered the study.

\section{Data Collection}

The study questionnaire includes two parts: demographic features such as age, gender, entrance year, field of study, hours of using the Internet and type of application. Yang's standard questionnaire on Internet addiction includes 20 items. Respondents answered the questionnaire based on 5 points Likert scale - from alternatives of none of them (1) to always (5). The range of test scores was from 0 to 100 . The higher score 
shows more dependency on Internet. After calculating the total score, the status of the users was determined as follows: the score lower than 20 shows independency (none-user), the score between 20 and 49 shows normal user, the score between 50 and 79 shows minor addiction (risky individuals) and the score between 80 and 100 indicates severe addiction.

Data Analysis

Data were analyzed using IBM SPSS Statistics for Windows, Version 19.0 (IBM Corp., Armonk, NY, USA). T statistical test and Chi-square test were done. The significance level has been considered 0.05.

Ethical Clearance

This research was approved with the Code of $K / 93 / 438$ by the Ethics Committee of Kerman University of Medical Sciences.

\section{Results}

Among 400 students, 245 (61.2\%) were female, medical field (32\%) and sophomores (31.5\%) (Table 1).

Table 1. Distribution of participants.

\begin{tabular}{lcc}
\hline \multicolumn{1}{c}{ Variables } & N & \% \\
\hline Gender & & \\
Male & 155 & 38.8 \\
Female & 245 & 61.2 \\
Field of Study & & \\
Medicine & 128 & 32.0 \\
Dentistry & 122 & 30.5 \\
Pharmacy & 90 & 22.5 \\
Nursing and Midwifery & 36 & 9.1 \\
Paramedical & 24 & 6.0 \\
Academic Year & & \\
First & 50 & 115.0 \\
Second & 126 & 31.5 \\
Third & 52 & 13.0 \\
Fourth & 67 & 14.3 \\
Fifth & 57 & 14.3 \\
Sixth & 31 & 7.8 \\
Seventh & 7 & 1.8 \\
\hline
\end{tabular}

Considering their familiarity with the Internet, $80.3 \%$ stated personal experience and $12.3 \%$ individuals stated educational periods held outside the university. The most locations of using the Internet were dormitories (21.0\%) and houses (43.5\%). Concerning hours of Internet use, $45.2 \%$ used the Internet more than two hours per day. One hundred sixty-eight individuals (42.0\%) stated that they used the Internet less than $15 \%$ for university activities. Ninety-two individuals $(23.0 \%)$ used the Internet for scientific searching topics. Eighty-six individuals (21.5\%) checked their e-mails daily. One hundred eighty-eight individuals (47.0\%) used VPN and 75.5\% were dissatisfied with Internet speed (Table 2). In the present research, 64.3\% had a poor dependency on the Internet. The percent of Internet use is none-users (75\%), poor users (64.2\%), risky users $(31.5 \%)$ and severe users (3.5\%), respectively. Figure 1 shows Internet dependency based on gender. 
Table 2. Distribution of participant according to Internet information.

\begin{tabular}{|c|c|c|}
\hline Variables & $\mathbf{N}$ & $\%$ \\
\hline \multicolumn{3}{|l|}{ Method Familiar to Internet } \\
\hline Out of University & 49 & 12.3 \\
\hline In University & 17 & 4.3 \\
\hline Self-Education & 321 & 80.3 \\
\hline Others & 6 & 1.5 \\
\hline No Answer & 7 & 1.7 \\
\hline \multicolumn{3}{|l|}{ Access to Internet } \\
\hline Home & 174 & 43.5 \\
\hline University & 75 & 18.7 \\
\hline Coffee Net & 13 & 3.3 \\
\hline Dormitory & 84 & 21.0 \\
\hline Others & 54 & 13.5 \\
\hline \multicolumn{3}{|l|}{ Daily Use of Internet } \\
\hline Less than Half of Hour & 52 & 13.0 \\
\hline Two Hours & 167 & 41.8 \\
\hline Greater than Two Hours & 181 & 45.2 \\
\hline \multicolumn{3}{|c|}{ Use of Internet for University Homework } \\
\hline Less than $15 \%$ & 168 & 42.0 \\
\hline $15-35 \%$ & 123 & 30.8 \\
\hline $35-70 \%$ & 67 & 16.7 \\
\hline Greater than $70 \%$ & 22 & 5.5 \\
\hline No Answer & 20 & 5.0 \\
\hline \multicolumn{3}{|l|}{ The Most Use Service } \\
\hline Advertising, Fun, Game & 29 & 7.3 \\
\hline Searching & 47 & 11.7 \\
\hline Social Media & 324 & 81.0 \\
\hline \multicolumn{3}{|l|}{ Use of Internet for Scientific Topic } \\
\hline Yes & 92 & 23.0 \\
\hline No & 245 & 61.3 \\
\hline No Answer & 63 & 15.7 \\
\hline \multicolumn{3}{|l|}{ Email Checking } \\
\hline Every Day & 86 & 21.5 \\
\hline At Least One Time in a Week & 220 & 55.0 \\
\hline Occasionally & 94 & 23.5 \\
\hline \multicolumn{3}{|l|}{ Access to VPN } \\
\hline Yes & 188 & 47.0 \\
\hline No & 212 & 53.0 \\
\hline \multicolumn{3}{|l|}{ Satisfy with Internet Speed } \\
\hline Yes & 97 & 24.3 \\
\hline No & 303 & 75.7 \\
\hline
\end{tabular}

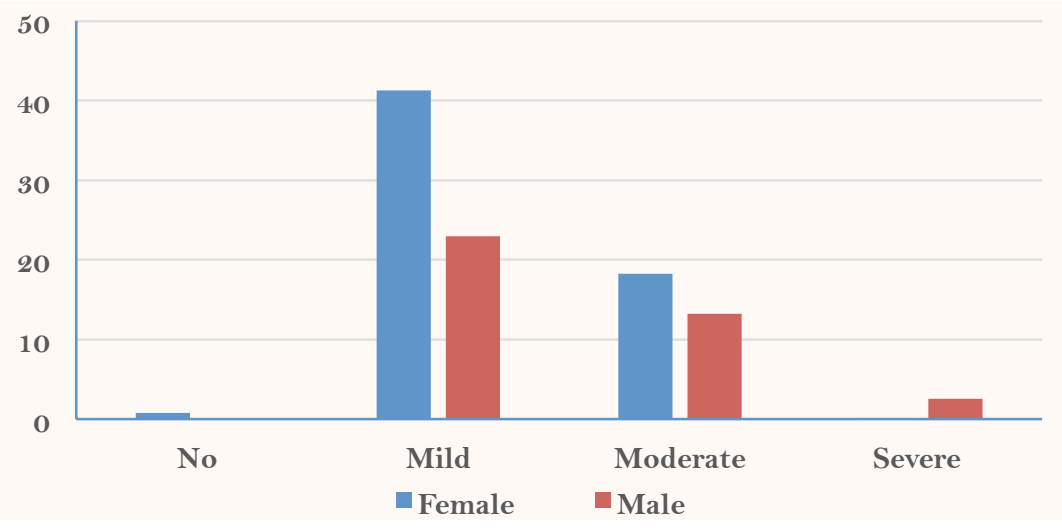

Figure 1. Internet dependency severity according to gender. 
Mean score of questionnaires was $43.98 \pm 15.92$, with ranges between 20 and 94 . The mean score of the questionnaire was $42.23 \pm 15.00$ for female students and $46.97 \pm 16.90$ for male students (from a maximum score of 125). No statistically significant difference was seen between both groups ( $\mathrm{p}=0.09)$. No statistically significant difference was observed between the mean score and the students' field of study $(\mathrm{p}=0.57)($ Table 3$)$. Nevertheless, no statistically significant difference was seen between entrance years and mean score $(p=0.45)$.

Table 3. Correlation between field of study and internet dependency.

\begin{tabular}{lccc}
\hline \multicolumn{1}{c}{ Field of Study } & Mean & SD & p-value \\
\hline Medicine & 42.23 & 14.47 & 0.57 \\
Dentistry & 44.25 & 14.73 & \\
Pharmacy & 45.70 & 19.92 & \\
Nursing and Midwifery & 43.54 & 17.36 & \\
Paramedical & 43.33 & 15.10 & \\
$\quad$ Total & 43.98 & 15.92 & \\
\hline
\end{tabular}

\section{Discussion}

In the present research, the mean score of Internet dependency was $43.98 \pm 15.92$, suggesting a moderate amount of Internet dependency. The mean score of Internet dependency of female and male students at Hormozgan medical sciences university was reported $36.11 \pm 23.66$ and $46.77 \pm 26.85$, respectively and it is in agreement with the results of the present research [19].

No statistically significant difference was seen between Internet dependency and gender in the present study, differently from that reported by other authors [20-23]. The difference mentioned may be due to the individuals' personalities who were being studied. Anxiety and depression lead to significant Internet addiction [24]. A significant relationship between gender and Internet dependency did not report in similar studies $[25,26]$ and this fact is in agreement with the present study. In this research, among 400 individuals, the percent of risky users was $31.5 \%$ and severe users were $3.5 \%$ ). A previous article showed that $27.2 \%$ were noneusers, 35.4\% were normal users, 20.9\% were risky users and 16.3\% were severe Internet addicted users [27]. Internet dependency of individuals under the study was lower than that in similar studies. Such difference may be due to the population under study. A previous study reported severe Internet dependency was $2.8 \%$, which is in agreement with the present research [20]. Severe Internet dependency was $0.2 \%$ in Greek medical students [28]. Internet addiction in medical students in a previous study was $47.7 \%$ [29], a result higher than that seen in this study.

In the present research, students mostly used internet for social networks and chats and it is in agreement with the study on Mashhad medical students, that showed the highest internet application was for chatting with new people and relationship with relatives and friends [30]. It has been shown that some of the Internet activities such as games and chats are more addictive than other activities [31]. In this research, 181 individuals used the Internet more than two hours daily. In research on Hormozgan medical students, 159 individuals used the Internet more than 15 hours [19] and this is in agreement with the results of the present study. It has been shown that an increase in hours of Internet use is one of the factors leading to Internet addiction [30]. In the present research, no statistically significant relationship was seen between the mean score of the questionnaire and the field of study. It is in disagreement with research conducted in Kermanshah medical students, which authors reported a significant difference between students of different fields of study and Internet addiction [32]. The reason for such difference may be the amount of access to the Internet and 
the personality of students under study. Also, it may be due to the difference between students' scientific level and high Internet application for doing scientific researches in the present investigation. In addition, no statistically significant difference was seen between the entrance year and Internet dependency in this research. Such results are in agreement with the study on medical students [20].

Among the limitations of the study is the cross-sectional design, which it is possible only to demonstrate results in Kerman Medical University students, and is not representative of all Iranian medical university students.

\section{Conclusion}

Most of the students were normal users of the Internet. Internet dependency has been paid more attention because the application of social networks has been increasing during recent months, and most of the individuals use the Internet for their activities.

\section{Authors' Contributions}

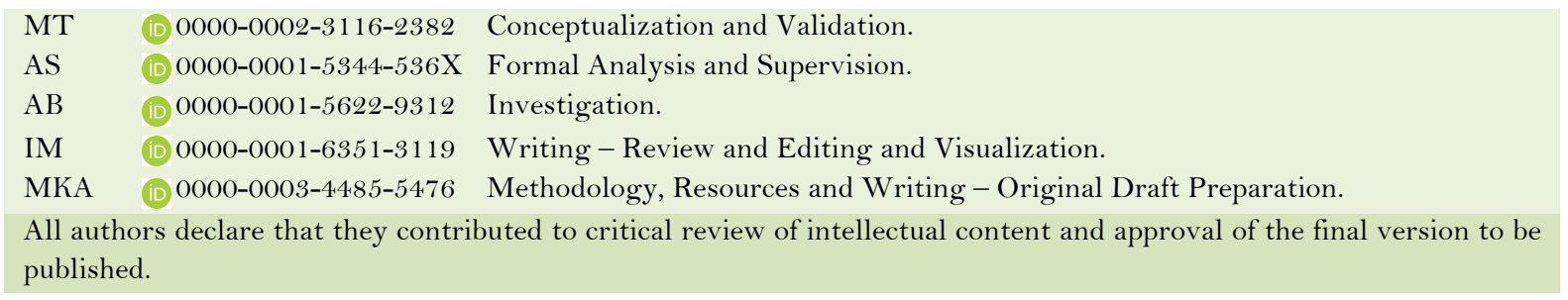

\section{Financial Support}

This study was supported by the Kerman University of Medical Sciences (Grant No. K/93/438).

\section{Conflict of Interest}

The authors declare no conflicts of interest.

\section{Acknowledgment}

We are very thankful to all the students that cooperated in the present study.

\section{References}

[1] Goel D, Subramanyam A, Kamath R. A study on the prevalence of internet addiction and its association with psychopathology in Indian adolescents. Indian J Psychiatry 2013; 55(2):140-3. https://doi.org/10.4103/0019-5545.111451

[2] Zare K, Kadivar P. Comparison self-efficacy between users and non users of internet. J Educ 2007; 23(1)1:111-34.

[3] Bessière K, Pressman S, Kiesler S, Kraut R. Effects of internet use on health and depression: a longitudinal study. J Med Internet Res 2010; 12(1):e6. https://doi.org/10.2196/jmir.1149

[4] Mirzaeian B, BaezatF, Khakpoor N. Internet addiction among students and its effect on mental health status. Infor Technol Educ Sci 2010; 2(1):141-62.

[5] Goldberg I. Internet Addiction. Available from: http://web.urz.uniheidelberg.de/Netzdienste/anleitung/wwwtips/8/addict.html. [Accessed on March 22, 2010].

[6] Vizeshfar F. Assessment of the internet addiction between Larian net users. J Fund Mental Health 2005; 7(25-26):2733.

[7] Sun-Woo K, Ran-do K. A Study of internet addiction: status, causes, and remedies - focusing on the alienation factor. Int J Human Ecol 2002; 3(1):1-19.

[8] Khoshakhlagh H, Faramarzi S.The relation of emotional intelligence and mental disorders with internet addiction in internet users university students. Addict Health 2012; 4(3-4):439-43. 
[9] Mark G. Does internet and computer "addiction” exist? Some case study evidence. Cyber Psychol Behav 2000; 3(2):211-8. https://doi.org/10.1089/109493100316067

[10] Waqas A, Rehman A, Malik A, Aftab R, Yar AA, Allah Yar A, et al. Exploring the association of ego defense mechanisms with problematic internet use in a Pakistani medical school. Psychiatry Res 2016; 243:463-8. https://doi.org/10.1016/j.psychres.2016.07.021

[11] Zhang MWB, Lim RBC, Lee C, Ho RCM. Prevalence of internet addiction in medical students: a meta-analysis. Acad Psychiatry 2018; 42(1):88-93. https://doi.org/10.1007/s40596-017-0794-1

[12] Dong G, Lu Q, Zhou H, Zhao X. Precursor or sequela: pathological disorders in people with internet addiction disorder. PLoS One 2011; 6(2):e14703. https://doi.org/10.1371/journal.pone.0014703

[13] Tang J, Yu Y, Du Y, Ma Y, Zhang D, Wang J. Prevalence of internet addiction and its association with stressful life events and psychological symptoms among adolescent internet users. Addict Behav 2014; 39(3):744-7. https://doi.org/10.1016/j.addbeh.2013.12.010

[14] Ranjbar M, Pardakhty A, Tahmipour B, Mohamadzadeh I. Novel CaO/polylactic acid nanoscaffold as dental resin nanocomposites and the investigation of physicochemical properties. Luminescence 2019; 34(3):360-7. https://doi.org/10.1002/bio.3617

[15] Ranjbar M, Noudeh GD, Hashemipour MA, Mohamadzadeh I. A systematic study and effect of PLA/Al2O3 nanoscaffolds as dental resins: mechanochemical properties. Artif Cells Nanomed Biotechnol 2019; 47(1):201-9. https://doi.org/10.1080/21691401.2018.1548472

[16] Eskandarizadeh A, Parizi MT, Goroohi H, Badrian H, Asadi A, Khalighinejad N. Histological assessment of pulpal responses to resin modified glass ionomer cements in human teeth. Dent Res J 2015; 12(2):144-9.

[17] Hashemipour MA, Ghasemi AR, Dogaheh MA, Torabi M. Effects of locally and systemically applied n-3 fatty acid on oral ulcer recovery process in rats. Wounds 2012; 24(9):258-66.

[18] Rekabi AR, Ashouri R, Torabi M, Parirokh M, Abbott PV. Florid cemento-osseous dysplasia mimicking apical periodontitis: a case report. Aust Endod J 2013; 39(3):176-9. https://doi.org/10.1111/j.1747-4477.2011.00325.x

[19] Dadipoor S, Zare F, Abdolrezaei F, Ghanbarnejad R, Hasanzadeh A, Safari Moradabadi A. Investigate internet addiction and effective factors among students in Hormozgan University of Medical Sciences. J Health Syst Res 2014; $10(3): 469-79$.

[20] Ghamari F, Mohammadbeigi A, Mohammadsalehi N, Hashiani AA. Internet addiction and modeling its risk factors in medical students, Iran. Indian J Psychol Med 2011;33(2):158-62. https://doi.org/10.4103/0253-7176.92068

[21] Deng YX, Hu M, Hu GQ, Wang LS, Sun ZQ. An investigation on the prevalence of internet addiction disorder in middle school students of Hunan province. Zhonghua Liu Xing Bing Xue Za Zhi 2007; 28(5):445-8.

[22] Tsai HF, Cheng SH, Yeh TL, Shih CC, Chen KC, Yang YC, et al. The risk factors of Internet addiction-a survey of university freshmen. Psychiatry Res 2009;167(3):294-9. https://doi.org/10.1016/j.psychres.2008.01.015

[23] Ceyhan AA. Predictors of problematic Internet use on Turkish university students. Cyberpsychol Behav 2008; 11(3):363-6. https://doi.org/10.1089/cpb.2007.0112

[24] Akin A, İskender M. Internet addiction and depression, anxiety and stress. Int Online J Educ Sci 2011; 3(1):138-48.

[25] Lin CH, Lin SL, Wu CP. The effects of parental monitoring and leisure boredom on adolescents' internet addiction. Adolescence 2009; 44(176):993-1004.

[26] Jelenchick LA, Becker T, Moreno MA. Assessing the psychometric properties of the Internet AddictionTest (IAT) in US college students. Psychiatry Res 2012; 196(2-3):296-301. https://doi.org/10.1016/j.psychres.2011.09.007

[27] Sepehrian F, Jokar L. The relationship of internet addiction with anxiety in A, B personality type. Res Cogn Behav Sci 2012; 2(2):17-30.

[28] Tsimtsiou Z, Haidich AB, Spachos D, Kokkali S, Bamidis P, Dardavesis T, et al. Internet addiction in Greek medical students: an online survey. Acad Psychiatry 2015; 39(3):300-4. https://doi.org/10.1007/s40596-014-0273-x

[29] Ali R, Mohammed N, Aly H. Internet addiction among medical students of Sohag University, Egypt. J Egypt Public Health Assoc 2017; 92(2):86-95. https://doi.org/10.21608/epx.2018.8946

[30] Salehi M, Khalili MN, Hojjat SK, Salehi M, Danesh A. Prevalence of internet addiction and associated factors among medical students from Mashhad, Iran in 2013. Iran Red Crescent Med J 2014; 16(5):e17256. https://doi.org/10.5812/ircmj.17256

[31] Ghasemzadeh L, Shahraray M, Moradi AR. The study of degree ofprevalence to internet addiction and its relation with loneliness and self esteemin high schools students of Tehran. J Educ 2007; 23(1):41-68.

[32] Mohammady Z, Khatony A, Hydary M, Bahreini M. Internet dependency in students of Kermanshah University of Medical Sciences. Iranian J Med Educ 2014; 13(12):1019-30. 